\title{
Lack of recall response to Tax in ATL and HAM/TSP patients but not in asymptomatic carriers of human T-cell leukemia virus type 1
}

\author{
Sharrón L. Manuel ${ }^{1}$, Mohit Sehgal ${ }^{1}$, John Connolly ${ }^{2}$, George Makedonas ${ }^{3}$, Zafar K. Khan ${ }^{1}$, \\ Jay Gardner ${ }^{3}$, James J. Goedert ${ }^{4}$, Michael R. Betts ${ }^{3}$, and Pooja Jain ${ }^{1, *}$ \\ ${ }^{1}$ Department of Microbiology and Immunology, Drexel University College of Medicine, \\ Philadelphia, PA 19104, USA \\ 2Singapore Immunology Network, Singapore 138648 \\ ${ }^{3}$ Department of Microbiology and Immunology, University of Pennsylvania School of Medicine, \\ Philadelphia, PA 19104, USA \\ ${ }^{4}$ National Cancer Institute, Division of Cancer Epidemiology and Genetics, Bethesda, MD 20892, \\ USA
}

\begin{abstract}
Purpose \& methods-The immunopathogenic mechanisms responsible for debilitating neurodegenerative and oncologic diseases associated with human T-cell leukemia virus type 1 (HTLV-1) are not fully understood. In this respect, a patient cohort from HTLV-1 endemic region that included seronegative controls (controls), asymptomatic carriers (ACs), and patients with adult T-cell leukemia (ATL) or HTLV-associated myelopathy/tropical spastic paraparesis (HAM/ TSP) was analyzed for $\mathrm{CD}^{+} \mathrm{T}$ cells polyfunctionality in response to the viral antigen Tax.
\end{abstract}

Results-Compared to ACs, ATL and HAM/TSP patients had lower frequency and polyfunctionality of CTLs in response to Tax suggesting dysfunction of $\mathrm{CD} 8^{+} \mathrm{T}$ cells in these individuals. As an underlying mechanism, programmed death-1 (PD-1) receptor was found to be highly unregulated in Tax-responsive as well as total CD8 ${ }^{+} \mathrm{T}$ cells from ATL and HAM/TSP but not from ACs and directly correlated with the lack of polyfunctionality in these individuals. Further, PD-1 expression showed a direct whereas MIP-1a expression had an indirect correlation with the proviral load providing new insights about the immunopathogenesis of HTLV-associated diseases. Additionally, we identified key cytokine signatures defining the immune activation status of clinical samples by the luminex assay.

Conclusions-Collectively, our findings suggest that reconstitution of fully functional CTLs, stimulation of MIP-1a expression, and/or blockade of the PD-1 pathway are potential approaches for immunotherapy and therapeutic vaccine against HTLV-mediated diseases.

\footnotetext{
*Address for correspondence: Pooja Jain, Ph.D., Department of Microbiology \& Immunology, and the Drexel Institute for Biotechnology \& Virology Research, Drexel University College of Medicine, 3805 Old Easton Road, Doylestown, PA 18902, USA, Phone (Office): 215-589-6441, (Lab): 215-589-6432, Fax: 215-489-4920, pjain@drexelmed.edu, Web: www.pjainlab.com.

Authorship

Contribution: J.J.G. provided the patients samples for the study. P.J., M.R.B., and Z.K.K. designed the study and experimental strategies. S.L.M. conducted the experimentation. J.C. helped in luminex experiment and data analyses. G.M./J.G. helped in polychromatic FACS analyses. S.L.M., M.S., and P.J. evaluated and interpreted data, structured data presentation, framed and edited the manuscript.
}

Conflict-of-interest disclosure: The authors declare that they have no competing interests. 


\section{Keywords}

Chronic viral infections; Cytotoxic T cell; $\mathrm{CD}^{+} \mathrm{T}$ cell; $\mathrm{CD}^{+} \mathrm{T}$ cell; Human T-cell leukemia virus type 1 ; HTLV-associated myelopathy/tropical spastic paraparesis; Tax

\section{Introduction}

The cytotoxic T lymphocyte (CTL) response and how it relates to HTLV-1-mediated diseases is the cornerstone for answering a major question concerning HTLV-1 pathogenesis, which is, why only a small percentage of infected individuals ( $5 \%)$ develop disease (ATL or HAM/TSP) remaining being asymptomatic carriers (ACs). Till date, there is no central paradigm that helps explain HTLV-1 immunopathogenesis (particularly in HAM/TSP), but rather two opposing theories that argue for or against the detrimental contribution of HTLV-1-specific CTLs to the observed inflammatory response. Studies performed in vitro have demonstrated that $\mathrm{CD}^{+} \mathrm{T}$ cells from infected individuals are capable of direct lysis of HTLV-1-infected CD4 ${ }^{+}$T cells (1-3). CTLs of HAM/TSP patients have also been reported to produce multiple cytokines and cytotoxic molecules $(4,5)$. While these studies support a protective role for the CTL immune response, others postulate it's detrimental role through autoimmune mechanisms leading to the clinical manifestation of HAM/TSP (6). A more likely explanation lies in the overall quality of HTLV-1-specific CTL response that determines the virus-host equilibrium and the ultimate disease outcome (7).

At any given time, only a small proportion ( 0.03\%-3\%) of infected cells express viral proteins, primarily Tax that is both oncogenic and immunogenic. The proliferation of Taxexpressing cells results in an increase in proviral load and drives expansion of Tax-specific CTLs. Both proviral load (8) and CTL response are significant determinants of disease outcome during HTLV-1 infection. ACs, ATL and HAM/TSP patients demonstrate a spectrum of proviral loads, which is controlled by CTL response and Tax expression. Therefore, understanding factors that control the balance of proviral load and Tax-specific CTL response is key to understanding HTLV-1 immunopathogenesis.

Recent approaches of evaluating antiviral activity of CTLs focus on their quality, and not frequency $(7,9-11)$. A fully primed effector response is now characterized by the secretion of certain cytokines (IFN- $\gamma$, TNF-a, and IL-2) by antigen-specific CTLs, their cytolytic potential (fast killer: granzymes/perforin or slow killer: membrane TNF, lymphotoxin, Fas ligand, and TRAIL), and proliferation in response to antigen. Polychromatic flow cytometry is a useful tool for evaluating unique immune signatures of an effective antiviral response since it allows multiple markers to be assessed on rare patient samples. In immune profiling of CTL responses, it is not just the number of markers that are coexpressed, but rather the combination of phenotypic and functional markers that define an appropriate pathogenspecific response. Different viruses have different immune evasion strategies thus requiring varying effector functions of $\mathrm{T}$ cells. Therefore, depending on the type and stage of infection, both categories of response profiles (memory and effector) are required.

Functional impairment of $\mathrm{T}$ cells has been observed during several chronic viral infections and many of the functional defects observed in the $\mathrm{CD} 8^{+} \mathrm{T}$ cell population are attributed to their expression of inhibitory molecules such as Programmed Death (PD)-1 receptor (1215). As CTLs pass through levels of exhaustion due to chronic antigen stimulation and extensive division (16), they witness higher antigen load, exhibit low CD4 dependence and gradually lose the qualities characteristic of fully functional CTLs. These molecular signatures of CTL exhaustion have been described (17) using lymphocytic choriomeningitis 
virus (LCMV) infection of mice in which high frequency of virus-specific CD8 $8^{+} \mathrm{T}$ cells is maintained by the persistence of viral antigen (18). During chronic infection by hepatitis $\mathrm{C}$ virus (HCV), viral proteins are implicated in actively suppressing the CTL responses (19). Since, Tax directs the mitotic division of infected T cells (20), we hypothesize that Taxspecific CTLs of diseased individuals undergo hierarchical exhaustion due to constant antigen stimulation. Once exhausted, these cells may not respond appropriately to Tax stimulus given exogenously as putative vaccine.

To test our hypothesis, we stimulated PBMCs from ACs, ATL, and HAM/TSP patients with Tax and a superantigen staphylococcal enterotoxin B (21) as well as a pool of peptides from cytomegalovirus (CMV), Epstein Barr virus and Influenza virus, known as CEF (22), and compared their polyfunctionality in parallel with controls, all from an HTLV-1 endemic region, Jamaica. While $\mathrm{CD} 8^{+} \mathrm{T}$ cells from both ATL and HAM/TSP patients respond well to SEB, they exhibit functional defects in responding to Tax rendering them ineffective at limiting HTLV-1 proviral loads. Superantigens (such as SEB), unlike conventional antigens, do not require processing and presentation by antigen-presenting cells. Rather, they bind directly to MHC class II molecules at a site distant from the peptide-binding groove and activate human $\mathrm{T}$ cells expressing V $\beta 3, \mathrm{~V} \beta 12, \mathrm{~V} \beta 14, \mathrm{~V} \beta 15, \mathrm{~V} \beta 17$, and V $\beta 20$ (23).

Therefore, SEB does not activate antigen-specific $\mathrm{CD} 8^{+} \mathrm{T}$ cells. Furthermore, upregulation of PD-1 and downregulation of MIP-1a with increase in the proviral load stood out as key signatures associated with chronic HTLV-1 infection irrespective of disease outcome. The heightened PD-1 expression was observed in both Tax-responsive as well as total CD8 ${ }^{+} \mathrm{T}$ cells from ATL and HAM/TSP patients but not ACs or control suggesting an overall dysfunction in this immune cell population in diseased individuals. This also explains why response to CEF was similar to that with Tax (both responses being antigen-specific). To the best of our knowledge, this is the first study that has compared the polyfunctionality (with respect to more than two functional markers) of $\mathrm{CD}^{+} \mathrm{T}$ cells in HTLV-1 carriers and diseased individuals (both ATL and HAM/TSP) in response to Tax stimulation, thus providing crucial insights for future anti-HTLV vaccine development.

\section{Materials and methods}

\section{Clinical samples}

A total of 68 samples (peripheral blood mononuclear cells) from Jamaica were obtained through collaboration with National Cancer Institute (Dr. James Goedert, Bethesda, MD) and processed under institutional review board guidelines. Patients were blinded throughout the study and for the purpose of statistical analyses categorized as Control, ACs, ATL, or HAM/TSP. Detailed subject information can be found in Table 1. Briefly, each group has 17 individuals including 11 females (numbered as F1-F11) and 6 males (numbered as M1-M6) except for HAM/TSP group that had 10 females (F1-F10) and 7 males (M1-M7). The median age range of females/males was 46 49/38 45 (Control), 42 43/37.5 60 (ACs), 49 48/38 53 (ATL), 48 45/46 59 (HAM/TSP). Being from Jamaican region, majority of the subjects were black.

\section{Proviral load detection by the TaqMan real-time polymerase chain reaction}

The proviral load was determined using an ABI PRISM 7700 Sequence Detector (Applied Biosystems, Carlsbad, CA) as previously described $(8,24,25)$. Briefly, genomic DNA was isolated using DNeasy Tissue Kit (Qiagen, Valencia, CA). For each sample, 100 ng genomic DNA was amplified in a standard real-time PCR reaction using primers specific to the HTLV-1 pX region (F/R 5'-3': ACAAAGTTAACCATGCTTATTATCAGC3/ ACACGTAGACTGGGTATCCGAA) and $\beta$-actin (F/R 5'-3': CACACTGTGCCCATCTACGA3'/5'CTCAGTGAGGATCTTCATGAGGTAGT). The 
TaqMan fluorescent probe was 5'TTCCCAGGGTTTGGACAGAGTCTTCT3' for the HTLV-I pX region and for $\beta$-actin was 5'ATGCCCTCCCCCATGCCATCCTGCGT3'. Standard curves were generated using DNA obtained from normal donor PBMCs (for $\beta$ actin) and from the rat cell line, TARL-2 (26). Proviral load represented as copies of pX per 100 PBMCs and calculated using the formula - (copy number of $\mathrm{pX}$ )/(copy number of $\beta$ $\operatorname{actin} / 2) \times 100$.

\section{Antibodies and dyes used for immunostaining}

The following antibodies/cell staining dyes were used for surface staining of PBMCs: antiCD57 Qdot 565 (AbD Serotec), anti-PD-1 APC (BioLegend), anti-CD14 Pacific Blue, antiCD16 Pacific Blue (BD Biosciences), anti-CD45RO Qdot 705 (Betts lab), anti-CD107a PECy5 (eBioscience), anti-CD4 PE-Cy5.5, anti-CD8 PE Texas Red, anti-CD27 Qdot 655, Aqua Blue live/dead dye (Invitrogen, Carlsbad, CA). The following antibodies were used for intracellular staining of PBMCs: anti-TNF-a PE-Cy7 (BD), anti-CD3 Qdot 585, anti-IFN-Y Alexa Fluor 700 (Invitrogen), anti-MIP-1a FITC (R\&D Systems), anti-Perforin (Tepnel). Pacific-blue conjugated antibodies were used as a "dump" gate to exclude monocytes/ macrophages, natural killer cells, and B cells and therefore gate on T cells. The aminereactive dye, Aqua Blue, was used to exclude the dead cells from analysis (27).

\section{T-cell stimulation and Immunostaining}

Overlapping peptides (15-mers overlapping by 11 amino acids) from the HTLV-1 Tax sequence were generated using PeptGen Peptide Generator software available online (28). A total of 84 different Tax peptides were synthesized (New England peptide, Gardner, MA) and used at a final concentration of $2 \mu \mathrm{g} / \mathrm{ml}$ for $6 \mathrm{~h}$. For one of the positive controls CEF was used to which $\sim 60 \%$ of individuals respond as determined by prior epitope mapping and optimization using an IFN- $\gamma$ Elispot (11). This pool consisted of approximately 70 total peptides each at $1 \mu \mathrm{g} / \mathrm{ml}$. A second positive control SEB at a concentration of $1 \mu \mathrm{g} / \mathrm{ml}$ was included along with a negative control (no peptide added). Cells were allowed to recover from cryopreservation as described (11) and one million cells were utilized for each condition. The antibody to CD107a was included during the stimulation procedure. Secretion inhibitors were added (Brefeldin A, $1 \mu \mathrm{g} / \mathrm{ml}$; monensin, $2 \mu \mathrm{M}$ ) in the presence of antibodies to CD28 and CD49d ( $1 \mu \mathrm{g} / \mathrm{ml}$ each). Following stimulation, the cells were pelleted and culture supernatant saved at $-80^{\circ} \mathrm{C}$ for luminex analyses. The pelleted cells were then washed and stained for appropriate markers to identify distinct memory CD8+ T cell subsets. The PBMCs were then fixed and permeabilized using a saponin-based staining procedure. Thereafter, cells were stained with antibodies against cytokines and other markers.

\section{Immunoprofiling of T cells}

The immunostaining of PBMCs has been performed according to (29). Phenotypes of CTLs were determined by flow cytometry utilizing a BD LSR II. Voltages were determined using 8xRainbow beads (Spherotech Inc., Lake Forest, IL) and unstained compensation beads (BD, San Jose, CA) run against a range of voltages, which were manually set in the FACSDiVa software (30). Five hundred thousand to one million events were acquired for analysis. Gates for each parameter were determined on the basis of fluorescence-minus-one gating $(31,32)$.

\section{2-plex Luminex ${ }^{\circledR}$ assay}

A human Cytokine/Chemokine Panel from Millipore was used for simultaneous detection of 42 analytes classified as chemokines (CCL22, Eotaxin, Fractalkine, GRO, IP-10, MCP-1, MCP-3, MIP-1a, MIP-1 $\beta$ ) and cytokines either proinflammatory (GM-CSF, IL-1a, IL-1 $\beta$, 
IL-8, IL-1ra, sCD40L), Th1 (IFN- $\gamma$, TNF-a, TNF- $\beta$, IL-15), Th2 (IL-2, IL-4, IL-5, IL-10, IL-3, IL-12p40, IL-12p70, IL-13), Th17 (G-CSF, IL-6, IL-9, IL-17A) or other immunomodulatory molecules (IFN- $\alpha 2$, sIL-2Ra) and growth factors (EGF, FGF-2, Flt-3 ligand, G-CSF, PDGF-AA, PDGF-AB/BB, TGF- $\alpha$ and VEGF). Entire procedure was performed as previously described (33). Briefly, cell culture supernatant that was saved from unstimulated, SEB-stimulated or Tax-stimulated PBMCs (6 h stimulation) was diluted fivefold and assay was performed in 96-well filter plates. For the detection step, samples were incubated for $30 \mathrm{~min}$ with streptavidin conjugated to R-phycoerythrin and analyzed in the Luminex $100^{\mathrm{TM}}$ instrument. Raw data was analyzed using Bioplex Manager software 6.0 (Bio-Rad). The cytokine standards supplied by the manufacturer were used to calculate the concentrations of the samples. The analytes that were below the detection range were not included in date interpretation. Also, samples that had a particular analyte below the detection range were excluded while calculating the median value.

\section{Statistical analysis and data interpretation}

The initial data analysis was performed using FlowJo version 8.8.7 software (Tree Star, Ashland, OR). The frequency of cells bearing markers for each possible functional combination, as well as the expression of any additional markers on those cells was determined using a Boolean gating algorithm. All reported data was corrected for background. To determine the significance within a group (i.e., between different stimulations), a two-tailed, paired nonparametric $t$ test was used (Wilcoxon matched pairs test). For comparisons between sample groups (control, AC, ATL, or HAM/TSP), a twotailed, unpaired nonparametric $t$ test was used (Mann-Whitney). The comparison was determined to be significant (*) if the $P$ value was less than or equal to ( $₫ 0.05$, very significant $(* *)$ if $\leq 0.01$, and extremely significant $(* * *)$ if $\leq 0.001$. Spearman correlations (2-tailed, 95\% CI) and other statistical values were obtained using Prism version 4C software (Graphpad Software Inc., La Jolla, CA). Other graphs were created either using Microsoft Excel version 12.2.9 or Simplified Presentation of Incredibly Complex Evaluations (SPICE) software version 4.3, obtained from Mario Roederer, NIH (34).

\section{Results}

\section{Proviral load distribution among clinical subjects}

At the onset of the study, we confirmed the HTLV-1 presence or absence in clinical samples and simultaneously quantitated their proviral loads as per the standard procedure. As expected, we did not detect any provirus in controls but observed varying levels in ACs, ATL and HAM/TSP patients (Fig. 1). In general, proviral loads of ATL and HAM/TSP patients were significantly higher than those of ACs $P<0.0001$ and $P=0.008$, respectively) similar to a previous report (35). Interestingly, ATL patients showed higher proviral loads than HAM/TSP (43 versus 21 average copies of pX per 100 PBMCs). Although a high proviral load is usually associated with HAM/TSP, some overlap exists in the ranges of proviral load between HAM/TSP patients and ACs. For example, HAM/TSP patients with low proviral loads (< $1 \%$ PBMCs infected) and ACs with high proviral loads (>3\% PBMCs infected) are reported (36) indicating that a high proviral load is neither necessary nor sufficient to cause HAM/TSP (37).

\section{IFN-y production by $\mathrm{CD}^{+} \mathrm{T}$ cells in response to Tax}

Once proviral loads were determined, all clinical samples were assayed for their ability to mount memory $\mathrm{CD} 8^{+} \mathrm{T}$ cell responses following antigen stimulation with Tax peptide pools and positive controls (CEF or SEB). The use of 84 Tax peptides spanning entire protein sequence expanded the repertoire of stimulated $\mathrm{T}$ cell clones and provided a way to measure a broad Tax-specific response (not just Tax 11-19 directed). Moreover, it would not have 
been feasible to carry out these polychromatic flow cytometric studies based on tetramer/ pentamer staining.

The general gating strategy is shown in Fig. 2A wherein only singlet events were included and first gated to remove the Aqua Blue bright dead cells, subsequently defined for total lymphocytes, $\mathrm{CD}^{+}$and $\mathrm{CD}^{+} \mathrm{T}$ cell population. The percentage of $\mathrm{CD} 8^{+} \mathrm{T}$ cells that produced IFN $-\gamma^{+}$in response to antigen stimulation was used as a readout of activation. As expected, at least $0.1 \%$ of $\mathrm{CD}^{+} \mathrm{T}$ cells of controls produced IFN- $\gamma$ in response to $6 \mathrm{~h}$ stimulation with both positive controls (SEB and CEF); however, response with SEB was more pronounced than $\mathrm{CEF}$ (2.17 versus $0.8 \% \mathrm{CD}^{+} / \mathrm{IFN}-\mathrm{\gamma}^{+}$cells) (Fig. $\left.2 \mathrm{~B}\right)$. Similar analysis of $\mathrm{CD}^{+} \mathrm{T}$-cell activation was performed on all the groups after stimulation with Tax and positive controls (SEB and CEF) (Fig. 2C). Overall, all groups showed significant response to SEB $(P<0.05)$ but only controls and ACs showed significant response to CEF $(P=0.08)$. With respect to Tax, we did not observe any response in controls as anticipated. ACs showed a significant increase in the frequency of $\mathrm{CD} 8^{+} / \mathrm{IFN}-\gamma^{+} \mathrm{T}$ cells $(P=0.006)$, whereas ATL and HAM/TSP patients did not show a significant response $(P=0.426$ and 0.733 , respectively). These results imply that ATL and HAM/TSP individuals might have a general defect in mounting an effective antigen-specific $\mathrm{CD} 8^{+} \mathrm{T}$ cell response as indicated by inability of their $\mathrm{CD}^{+} \mathrm{T}$ cells to produce IFN- $\gamma$ upon $\mathrm{CEF}$ or Tax stimulation.

\section{Differentiation and activation state of $\mathrm{CD8} 8^{+} \mathrm{T}$ cells among clinical groups}

Determining mechanisms that allow the rapid generation and maintenance of effector memory $\mathrm{T}$ cells is the key to improving the quality of protective immune responses. Specific subsets of human memory T cells are defined on the basis of their expression of CD27 or CCR7 in combination with CD45RA or CD45RO. For this study, we used the markers CD27 and CD45RO and did not observe significant changes in their expression upon SEB, CEF or Tax stimulation (Fig. 3). This could be due to short-term culture (6 h) of PBMCs that is not sufficient to change CD27 and CD45RO profile and/or expand specific T cell population. Therefore, we compared basal (non-stimulated) levels of naïve $\left(\mathrm{CD} 27^{+} /\right.$ $\left.\mathrm{CD} 45 \mathrm{RO}^{-}\right)$, effector $\left(\mathrm{CD} 27^{-} / \mathrm{CD} 45 \mathrm{RO}^{-}\right)$, central memory $\left(\mathrm{CD} 27^{+} / \mathrm{CD}^{2} 5 \mathrm{RO}^{+}\right)$and effector memory $\left(\mathrm{CD} 27^{-} / \mathrm{CD}^{2} 5 \mathrm{RO}^{+}\right) \mathrm{CD}^{+} \mathrm{T}$ cells between control and HTLV infected individuals. Only significant difference was observed in the frequency of naïve $\mathrm{T}$ cell compartment in ATL patients $(P=0.04$, Fig. 3A) that corresponded with higher frequency of effector cells in the same group albeit with low significance $(P=0.2)$.

\section{Expression of various T-cell functional markers on IFN- $\mathrm{y}^{+} / \mathrm{CD}^{+}{ }^{+} \mathrm{T}$ cells}

Besides producing IFN- $\gamma$, activated $\mathrm{CD} 8^{+} \mathrm{T}$ cells upregulate certain key molecules, which play a critical role in the antiviral immune response. For example, CD107a (T-cell degranulation marker), de novo synthesized perforin, MIP-1 $\alpha$, and TNF- $\alpha$ are four such molecules whose coexpression along with IFN- $\gamma$ is a better predictor of CTL quality (11). Therefore, we studied the expression of these functional markers on IFN- $\gamma^{+} / \mathrm{CD} 8^{+} \mathrm{T}$ cells upon stimulation with CEF, SEB and Tax. Since the frequency of IFN- $\gamma$ producing CD8 ${ }^{+} \mathrm{T}$ cells was very low in non-stimulated samples, we omitted this variable during the statistical comparison of data (Fig. 4). After SEB and CEF stimulation, cells from all four groups exhibited no significant differences in terms of expression of any of the functional marker. However, some interesting differences were observed among groups in response to Tax. First, perforin levels were high in ACs $(P=0.0174)$ and ATL $(P=0.0234)$ but not in HAM/ TSP patients as compared to controls. Similarly, levels of MIP-1a and TNF- $\alpha$ were significantly higher in ACs ( $P=0.0105$ and 0.0149 , respectively) but not in ATL or HAM/ TSP patients compared to controls. In addition, TNF-a levels in ACs were found to be significantly higher as compared to ATL patients as well $(P=0.0377)$. Overall, this data 
suggest a lack of recall response to Tax in diseased individuals being more pronounced in HAM/TSP patients.

\section{CTLs in ATL and HAM/TSP patients upregulate PD-1 expression}

The PD-1/PD-L1 pathway has been implicated as a cause of T-cell dysfunction in chronic viral infections $(17,38-40)$. Therefore, we assessed the expression of PD-1 on CD ${ }^{+} / \mathrm{IFN}-\gamma^{+}$ $\mathrm{T}$ cells as well as total $\mathrm{CD}^{+} \mathrm{T}$ cells after SEB and Tax stimulation. In response to SEB, we observed no statistically significant differences in PD- 1 expression on $\mathrm{CD}^{+} / \mathrm{IFN}-\gamma^{+} \mathrm{T}$ cells and total $\mathrm{CD}^{+} \mathrm{T}$ cells between the four groups. However, in response to Tax stimulation, there was significantly higher expression of PD-1 in ATL and HAM/TSP patients compared to controls $(P=0.012$ and 0.001 , respectively) and ACs $(P=0.0148$ and 0.0375 , respectively). $\mathrm{PD}-1$ expression on total $\mathrm{CD}^{+} \mathrm{T}$ cells was also significantly higher in ATL and HAM/TSP patients compared to control $(P=0.0043$ and 0.0019 , respectively $)$ and ACs $(P=0.0127$ and 0.0048 , respectively) upon Tax stimulation (Fig. 5B). This was more apparent while comparing the median values of $\mathrm{PD}-1^{+} \mathrm{CD} 8^{+} \mathrm{T}$ cells among all groups (Fig. 5C). It is important to note that ATL individuals (compared to ACs) had significant upregulation of PD- 1 on $\mathrm{CD}^{+} / \mathrm{IFN}_{-} \mathrm{\gamma}^{+} \mathrm{T}$ cells as well as total $\mathrm{CD}^{+} \mathrm{T}$ cells in response to CEF. Previous studies on HIV-infected patients have also shown that increased PD-1 expression is not limited to $\mathrm{HIV}$-specific $\mathrm{CD}^{+} \mathrm{T}$ cells, but is found on all $\mathrm{CD}^{+} \mathrm{T}$ cells in general $(41,42)$.

\section{Reduced polyfunctionality correlate with heightened PD-1 expression}

The functional evaluation of $\mathrm{T}$ cell responses has in recent years advanced from singleparameter (IFN-Y-secretion) to much more complex multiparametric measurements. CTLs with multiple effector functions are more effective in controlling the virus. SPICE is a tool commonly used to depict these polyfunctionality profiles, in which each slice of the pie represents the number of functions that $\mathrm{CD}^{+} \mathrm{T}$ cells possess (34). Thus utilizing this tool we evaluated the profile of $\mathrm{CD}^{+} \mathrm{T}$ cells from each clinical category in response to $\mathrm{CEF}$, SEB and Tax (Fig. 6). The largest number of functions that were coexpressed among each category was five since none of the groups expressed all six functions. Interestingly, ATL $\mathrm{CD}^{+} \mathrm{T}$ cells stimulated with CEF coexpressed five functional markers as depicted by the red slice indicating a better response to $\mathrm{CEF}$ exclusively in this group. A proportion of $\mathrm{CD}^{+}$ $\mathrm{T}$ cells in control and ACs also expressed five markers in response to SEB. The coexpression of four functional markers was seen in controls, ACs and HAM/TSP patients (albeit low) in response to SEB and only in ACs in response to Tax (Fig. 6). At large, three or two functional markers (depicted by yellow and purple slice, respectively) were present in each category with varying levels but ACs were found to be more polyfunctional than ATL and HAM/TSP patients. Majority of the $\mathrm{CD}^{+} \mathrm{T}$ cells from diseased individuals expressed only one marker as depicted by the green slice. Moreover, PD-1 expression (depicted by an arc) dominated the overall $\mathrm{T}$ cell response in these patients, especially on cells that were functionally less competent (expressing $\leq 2$ markers).

\section{Opposite dynamics of PD-1 and MIP-1a with proviral load}

The proviral loads of ACs, ATL, and HAM/TSP as shown in Fig. 1 were compared to the levels of individual markers and a Spearman correlation coefficient $\left(\mathrm{R}^{2}\right)$ was calculated using Prism 4.0 C software. Of all markers analyzed, PD-1 and MIP-1a demonstrated a strong correlation with proviral load (Fig. 7). Total percentage of PD-1 expressing CD8 ${ }^{+} \mathrm{T}$ cells correlated positively with proviral loads in ACs $\left(\mathrm{R}^{2}=0.905, P<0.0005\right)$, ATL $\left(\mathrm{R}^{2}=\right.$ $0.856, P<0.0001)$ and HAM/TSP $\left(\mathrm{R}^{2}=0.996, P<0.0001\right)$. In contrast to this, MIP-1a negatively correlated with proviral load in all three groups $\left(\mathrm{R}^{2}=0.994\right.$ and $P<0.0001$ in AC, $\mathrm{R}^{2}=0.910$ and $P<0.0001$ in ATL, and $\mathrm{R}^{2}=0.999$ and $P<0.0001$ in HAM/TSP). Beside these two markers, IFN- $Y$ had a slight negative correlation with proviral load in ACs 
$\left(\mathrm{R}^{2}=0.740\right.$ and $\left.P=0.026\right)$ but not in ATL and HAM/TSP patients. These results identified two key signatures of immune response that correlate with the proviral load in HTLVinfected individuals irrespective of their disease state.

\section{Extracellular cytokine/chemokine milieu in response to SEB and Tax}

Assessment of cytokine/chemokine secretion profile in response to antigenic stimulation provides valuable clues about the type of T-cell response generated. We therefore compared the cytokine/chemokine secretion profile of clinical samples by performing luminex analyses of cell culture supernatant after stimulation of their PBMCs with SEB or Tax for 6 h (Fig. 8). Of total 42 analytes, levels of nine analytes were higher upon stimulation with SEB but not Tax in ACs. These analytes were IL-3 ( $P=0.0293)$, IL-13 $(P=0.0489)$, IP-10 $(P=0.0101)$, PDGF-AA $(P=0.0259)$, sCD40L $(P=0.0015)$, sIL-2Ra $(P=0.0083)$, TNF-a $(P=0.0418)$, TNF- $\beta(P=0.0287)$, and GM-CSF $(P=0.0015)$. In ACs, IL-15 levels were fairly high upon stimulation with Tax but not SEB $(P=0.07)$. In ATL patients, CX3CL1 ( $P$ $=0.00482), \mathrm{IFN}-\mathrm{a} 2(P=0.0487), \mathrm{MCP}-3(P=0.0047)$ and $\mathrm{sCD} 40 \mathrm{~L}(P=0.0025)$ were elevated in response to SEB. In case of HAM/TSP patients, only one cytokine IL-6 was significantly higher again in response to SEB but not Tax $(P=0.0495)$. While not statistically significant, one cytokine (sIL-2Ra) was released at greater level in HAM/TSP patients in response to Tax. Overall, these results showed a generalized lack of response to Tax and some response to SEB primarily in ACs but not in ATL or HAM/TSP patients. This is consistent with our previous observation of IFN- $\gamma$ upregulation on $\mathrm{CD}^{+} \mathrm{T}$ cells in response to SEB but not Tax. It is important to note that some analytes were below the limit of detection, which could possibly be due to their short half-lives (less than $6 \mathrm{~h}$ ). Given limited number of cells, luminex analysis at different periods of Tax stimulation was not feasible.

\section{Discussion}

HTLV-1-specific CTLs play a crucial role in containing the proliferation of HTLV-1infected T cells $(43,44)$ but their actual role (beneficial or detrimental) in disease pathogenesis is controversial. Therefore, investigation of T-cell signatures associated with infection outcome holds considerable importance in terms of designing an effective vaccine against ATL or HAM/TSP. Thus far major emphasis has been given on characterizing CD8 T cells response against HTLV-1 based on the frequency of Tax-specific CTLs (1, 44-48). An extensive analysis of their polyfunctionality as presented here has not been performed yet. Further, since a very small percentage of HTLV-infected individuals develop disease, few immunological investigations like ours have been possible on all four categories of samples (controls, ACs, ATL, and HAM/TSP) from one particular region. Most published studies of this nature were conducted on very few samples due to the limitations associated with obtaining samples from geographical areas of higher disease prevalence (49) as well as the use of frozen PBMCs for immunological investigations. We too have first conducted a pilot experiment on few control samples from the same region and confirmed that there was not much difference in the expression levels of studied functional markers between fresh and frozen PBMCs (data not shown).

Most of the HTLV-1-specific CTLs are directed against Tax (44, 46, 50, 51). Therefore, before comprehensive immunological investigations, we determined IFN- $\gamma$ producing capabilities of all subjects in response to Tax overlapping peptides and a superantigen SEB (Fig. 2C). An overall positive response to SEB reaffirmed the functional competence of clinical samples and indicated responsiveness of $\mathrm{CD}^{+} \mathrm{T}$ cells from diseased individuals to a general stimulus. However, lack of IFN- $\gamma$ production by ATL and HAM/TSP in response to both Tax and CEF is suggestive of a general defect in mounting antigen-specific T-cell response in diseased individuals. This could be due to high proviral loads (Fig. 1) leading to 
chronic antigen stimulation and T cell exhaustion previously shown for HTLV-1 and other chronic viruses (52-57). We then compared the frequencies of various phenotypically distinct subsets of $\mathrm{CD}^{+} \mathrm{T}$ cells both at basal level as well as upon CEF/SEB/Tax stimulation and did not observe expansion of naïve, effector or memory $\mathrm{T}$ cells in any group (Fig. 3). This is contradictory to another study (58), which reported rapid ex vivo expansion of effector memory T cells in PBMCs of HAM/TSP patients in response to Tax. It is important to note that this study cultured the $\mathrm{T}$ cells for a longer duration compared to short $6 \mathrm{~h}$ stimulation in our study. Only significant change was observed in the low frequency of naïve T cells in ATL patients that could be related to unusually high proviral load seen in this group of Jamaican cohort.

Having measured the frequency of CTLs, we measured the expression of four key functional molecules associated with effector CTLs (CD107a, de-novo synthesized perforin, MIP-1a and TNF- $\alpha$ ) on $\mathrm{CD}^{+} / \mathrm{IFN}-\gamma^{+} \mathrm{T}$ cells (Fig. 4). Similar to observations made for IFN- $\gamma$, ACs demonstrated a good overall response to CEF, SEB, and Tax that was limited to SEB in ATL and HAM/TSP patients confirming defect in antigen-specific CD8 ${ }^{+} \mathrm{T}$-cell response. With respect to individual marker expression we could find some parallels with existing literature. For example, CD107a expression was shown to be higher in ACs compared to HAM/TSP patients (5). Similarly, gene expression profiling of CD8 ${ }^{+} \mathrm{T}$ cells indicated low perforin expression in HAM/TSP patients (59). It has been suggested that excess production of inflammatory cytokines is one of the factors that contribute to the development of HAM/ TSP $(60,61)$. In corroboration with this, we observed moderately significant upregulation of TNF-a $(P=0.1478)$ and MIP-1a $(P=0.084)$ in HAM/TSP patients as compared to controls.

In order to understand the cause of $\mathrm{CD} 8^{+} \mathrm{T}$ cells dysfunctions, we specifically measured the expression of T-cell inhibitory receptor, PD-1. The interaction of PD-1 with its ligand, PDL1 (expressed primarily on antigen presenting cells) has been shown to negatively regulate cytokine production and proliferation of T cells $(62,63)$. PD-1 has been shown to be upregulated on HTLV-1-specific CTLs in ATL (64) and HAM/TSP patients (38), but other more recent studies suggest downregulation of PD-1 expression on HTLV-1-specific CTLs of HAM/TSP patients (65-67). However, it is unclear how these expression levels compare to those found in ACs because of conflicting reports. Our results as presented in figure 5A show PD-1 upregulation on Tax but not SEB-responsive CTLs from ATL and HAM/TSP patients compared to both controls and ACs. Similar observations were made while studying the expression of PD-1 on total CD8 ${ }^{+} \mathrm{T}$ cells in response to Tax (Fig. 5B and C) implicating this molecule as the key factor contributing towards lack of recall response to Tax in $\mathrm{CD}^{+}$ $\mathrm{T}$ cells from diseased individuals. Interestingly, ATL individuals (compared to ACs) had significant upregulation of PD- 1 on $\mathrm{CD}^{+} / \mathrm{IFN} \gamma^{+} \mathrm{T}$ cells as well as on total $\mathrm{CD} 8^{+} \mathrm{T}$ cells in response to CEF confirming an overall dysfunction of CD8 T-cell population in the diseased individuals.

The hallmark of an effective adaptive immune response is the polyfunctionality of T cells, which is defined by their ability to express a number of functional markers and soluble factors. In order to further strengthen the link between PD- 1 and $\mathrm{CD}^{+} \mathrm{T}$ cell polyfunctionality, we characterized the simultaneous expression of key markers on stimulated $\mathrm{CD}^{+} \mathrm{T}$ cells in all four clinical groups (Fig. 6). Although all effector functions were not absent, CTLs from diseased individuals exhibited lower degree of polyfunctionality compared to ACs in terms of co-expression of 2 or more markers. Interestingly, we noticed that lower the number of markers, higher the level of PD-1 expression. PD-1/PD-L1 thus emerges as a major pathway involved in reduced polyfunctionality and poor recall response to Tax in ATL and HAM/TSP patients. 
Since proviral load is proven to be a major determining factor of HTLV-specific CD8 T cell response, we determined correlation between individual proviral load and corresponding immune marker expression. Of all markers analyzed, only PD-1 and MIP-1a were found to have strong correlation with proviral load (Fig. 7). PD-1 expression was positively correlated with the proviral load in ACs, ATL, and HAM/TSP patients suggesting that higher proviral load may skew the balance of the immune system towards a more tolerogenic state leading to impairment of effective T-cell response. Since ACs have low proviral load and hence low frequency of tolerogenic $\mathrm{CD} 8^{+} \mathrm{T}$ cells explaining their ability to control the virus. On the other hand, MIP-1a expression on total $\mathrm{CD} 8^{+} \mathrm{T}$ cells negatively correlated with the proviral load. MIP-1a is involved in the recruitment and activation of leukocytes during antiviral immune response and it is possible that higher proviral load in ATL and HAM/TSP patients suppresses its secretion thereby affecting the generation of antiviral immune response.

Soluble factors like cytokines and chemokines are central to the immune response, exerting direct effector functions or enabling T-cell recruitment or expansion. Luminex assay is an effective mean of detecting multiple soluble factors released by low number of cells. Thus, we used this assay to quantitate several different types of analytes in cell culture supernatants of PBMCs stimulated with SEB or Tax. Interestingly enough, cells from ACs did not release many factors in response to Tax as they did in response to SEB (Fig. 8), which could be due to the low frequency of Tax expressing cells in these individuals that is also true for ATL patients $(1,48)$ that have not shown much response with Tax as well. While HAM/TSP patients have large number of Tax-expressing cells but as indicated above majority of these cells are dysfunctional or exhausted. Both ATL and HAM/TSP showed some response to SEB but in a differential manner. ATL patients produced higher amounts of chemokines, CX3CL1 and MCP-3 and proinflammatory cytokine sCD40L while HAM/ TSP patients secreted higher levels of IL-6 (a proinflammatory cytokine), which is not surprising given the fact that these patients have two distinct immune and clinical outcomes.

The current study favors the notion that CTL quality (lytic efficiency), and not quantity, is an important predictor of HTLV-1 infection outcome (10, 20, 59, 68, 69). High lytic efficiency of HTLV-1-specific CTLs results in low HTLV-1 antigen load and thus low activation of antigen presenting cells like DCs, which then promote moderate (protective) $\mathrm{T}$ cell responses and asymptomatic carriage of the virus. In contrast, low lytic efficiency of CTLs results in high HTLV-1 antigen load and subsequent overactivation of DCs. Interferon production by persistently over activated DCs can then lead to inflammatory tissue damage (HAM/TSP). Alternatively, high HTLV-1 antigen load can lead to prolonged clonal proliferation of infected $\mathrm{T}$ cells, resulting in accumulation of secondary mutations and DNA damage and the emergence of one or more malignant $\mathrm{T}$ cell clone (leukemia/lymphoma). Collectively, results of this study suggest that restoration of $\mathrm{CD} 8^{+} \mathrm{T}$-cell response in HTLV-1-infected individuals by PD-1 blockade can enhance viral clearance and thus protect against HTLV-1-mediated diseases. Nevertheless, findings in this study may be cohortspecific and the involvement of other negative regulatory pathways during HTLV-1 infection cannot be ruled out. Comparison of global gene expression profiles between exhausted $\mathrm{CD} 8^{+} \mathrm{T}$ cells and functional virus-specific effector and memory $\mathrm{CD} 8^{+} \mathrm{T}$ cells has identified upregulation of many inhibitory receptors such as LAG-3, CTLA-4, 2B4, NKG2A, GP49b, Tim-3, etc., in addition to PD-1 (17). Therefore, in future studies, we plan to understand in-depth mechanisms of T-cell exhaustion during chronic HTLV-1 infection and also investigate whether other inhibitory molecules operate in synergism with PD-1 in ATL and/or HAM/TSP individuals. 


\section{Acknowledgments}

This work was supported by the Public Health Service, National Institutes of Health wherein PJ was funded through NIAID R01 AI077414 and NCI R01 CA054559 while ZKK was funded through NIAID R21 AI 093172-01. In addition, we thank the Philadelphia NeuroAIDS Training Grant: T32 MH079785 that has supported efforts of S. Manuel. We also wish to acknowledge Ms. Rasha el Baz's contribution for formatting the manuscript and assisting in the submission process.

\section{References}

1. Arnulf B, Thorel M, Poirot Y, Tamouza R, Boulanger E, Jaccard A, et al. Loss of the ex vivo but not the reinducible CD8+ T-cell response to Tax in human T-cell leukemia virus type 1-infected patients with adult T-cell leukemia/lymphoma. Leukemia. 2004; 18(1):126-32. Epub 2003/10/24. [PubMed: 14574331]

2. Hanon E, Hall S, Taylor GP, Saito M, Davis R, Tanaka Y, et al. Abundant tax protein expression in CD4+ T cells infected with human T-cell lymphotropic virus type I (HTLV-I) is prevented by cytotoxic T lymphocytes. Blood. 2000; 95(4):1386-92. [PubMed: 10666215]

3. Hanon E, Stinchcombe JC, Saito M, Asquith BE, Taylor GP, Tanaka Y, et al. Fratricide among CD8(+) T lymphocytes naturally infected with human T cell lymphotropic virus type I. Immunity. 2000; 13(5):657-64. Epub 2000/12/15. [PubMed: 11114378]

4. Greten TF, Slansky JE, Kubota R, Soldan SS, Jaffee EM, Leist TP, et al. Direct visualization of antigen-specific T cells: HTLV-1 Tax11-19- specific CD8(+) T cells are activated in peripheral blood and accumulate in cerebrospinal fluid from HAM/TSP patients. Proc Natl Acad Sci U S A. 1998; 95(13):7568-73. [PubMed: 9636190]

5. Sabouri AH, Usuku K, Hayashi D, Izumo S, Ohara Y, Osame M, et al. Impaired function of human T-lymphotropic virus type 1 (HTLV-1)-specific CD8+ T cells in HTLV-1-associated neurologic disease. Blood. 2008; 112(6):2411-20. Epub 2008/05/27. [PubMed: 18502825]

6. Matsuura E, Yamano Y, Jacobson S. Neuroimmunity of HTLV-I Infection. J Neuroimmune Pharmacol. 2010; 5(3):310-25. Epub 2010/05/04. [PubMed: 20437106]

7. Kattan T, MacNamara A, Rowan AG, Nose H, Mosley AJ, Tanaka Y, et al. The avidity and lytic efficiency of the CTL response to HTLV-1. J Immunol. 2009; 182(9):5723-9. Epub 2009/04/22. [PubMed: 19380819]

8. Nagai M, Usuku K, Matsumoto W, Kodama D, Takenouchi N, Moritoyo T, et al. Analysis of HTLV-I proviral load in 202 HAM/TSP patients and 243 asymptomatic HTLV-I carriers: high proviral load strongly predisposes to HAM/TSP. J Neurovirol. 1998; 4(6):586-93. Epub 1999/03/05. [PubMed: 10065900]

9. Asquith B, Mosley AJ, Barfield A, Marshall SE, Heaps A, Goon P, et al. A functional CD8+ cell assay reveals individual variation in $\mathrm{CD} 8+$ cell antiviral efficacy and explains differences in human T-lymphotropic virus type 1 proviral load. J Gen Virol. 2005; 86(Pt 5):1515-23. Epub 2005/04/16. [PubMed: 15831965]

10. Bangham CR. CTL quality and the control of human retroviral infections. Eur J Immunol. 2009; 39(7):1700-12. Epub 2009/07/08. [PubMed: 19582737]

11. Makedonas G, Hutnick N, Haney D, Amick AC, Gardner J, Cosma G, et al. Perforin and IL-2 upregulation define qualitative differences among highly functional virus-specific human CD8 T cells. PLoS Pathog. 2010; 6(3):e1000798. Epub 2010/03/12. [PubMed: 20221423]

12. McMahan RH, Golden-Mason L, Nishimura MI, McMahon BJ, Kemper M, Allen TM, et al. Tim-3 expression on PD-1+ HCV-specific human CTLs is associated with viral persistence, and its blockade restores hepatocyte-directed in vitro cytotoxicity. J Clin Invest. 2010; 120(12):4546-57. Epub 2010/11/19. [PubMed: 21084749]

13. Day CL, Kaufmann DE, Kiepiela P, Brown JA, Moodley ES, Reddy S, et al. PD-1 expression on $\mathrm{HIV}$-specific T cells is associated with T-cell exhaustion and disease progression. Nature. 2006; 443(7109):350-4. [PubMed: 16921384]

14. Radziewicz H, Ibegbu C, Fernandez M, Workowski K, Obideen K, Wehbi M, et al. Liverinfiltrating lymphocytes in chronic human hepatitis $\mathrm{C}$ virus infection display an exhausted 
phenotype with high levels of PD-1 and low levels of CD127 expression. J Virol. 2007; 81:254553. [PubMed: 17182670]

15. Zhang J, Zhang Z, Wang X, Fu J, Yao J, Jiao Y, et al. PD-1 up-regulation is correlated with HIVspecific memory CD8+ T-cell exhaustion in typical progressors but not in long-term nonprogressors. Blood. 2007; 109:4671-8. [PubMed: 17272504]

16. Shin H, Blackburn SD, Blattman JN, Wherry EJ. Viral antigen and extensive division maintain virus-specific CD8 T cells during chronic infection. J Exp Med. 2007; 204(4):941-9. Epub 2007/04/11. [PubMed: 17420267]

17. Wherry EJ, Ha SJ, Kaech SM, Haining WN, Sarkar S, Kalia V, et al. Molecular signature of CD8+ T cell exhaustion during chronic viral infection. Immunity. 2007; 27(4):670-84. [PubMed: 17950003]

18. Shin H, Wherry EJ. CD8 T cell dysfunction during chronic viral infection. Curr Opin Immunol. 2007; 19(4):408-15. Epub 2007/07/28. [PubMed: 17656078]

19. Hiroishi K, Eguchi J, Ishii S, Hiraide A, Sakaki M, Doi H, et al. Immune response of cytotoxic T lymphocytes and possibility of vaccine development for hepatitis $\mathrm{C}$ virus infection. J Biomed Biotechnol. 2010; 2010:263810. Epub 2010/05/29. [PubMed: 20508848]

20. Asquith B, Mosley AJ, Heaps A, Tanaka Y, Taylor GP, McLean AR, et al. Quantification of the virus-host interaction in human T lymphotropic virus I infection. Retrovirology. 2005; 2:75. Epub 2005/12/13. [PubMed: 16336683]

21. Sebastian D, Nayiager S, York DY, Mody GM. Lack of association of Human T-cell lymphotrophic virus type $1(\mathrm{HTLV}-1)$ infection and rheumatoid arthritis in an endemic area. Clin Rheumatol. 2003; 22(1):30-2. [PubMed: 12605314]

22. Charles J, Di Domizio J, Salameire D, Bendriss-Vermare N, Aspord C, Muhammad R, et al. Characterization of circulating dendritic cells in melanoma: role of CCR6 in plasmacytoid dendritic cell recruitment to the tumor. J Invest Dermatol. 2010; 130(6):1646-56. Epub 2010/03/12. [PubMed: 20220766]

23. Marrack P, Kappler J. The Staphylococcal Enterotoxins and Their Relatives. Science. 1990; 248(4956):705-11. [PubMed: 2185544]

24. Nagai M, Kubota R, Greten TF, Schneck JP, Leist TP, Jacobson S. Increased activated human T cell lymphotropic virus type I (HTLV-I) Tax11-19-specific memory and effector CD8+ cells in patients with HTLV-I-associated myelopathy/tropical spastic paraparesis: correlation with HTLV-I provirus load. J Infect Dis. 2001; 183(2):197-205. Epub 2000/12/20. [PubMed: 11120926]

25. Yamano Y, Nagai M, Brennan M, Mora CA, Soldan SS, Tomaru U, et al. Correlation of human Tcell lymphotropic virus type 1 (HTLV-1) mRNA with proviral DNA load, virus-specific CD8(+) T cells, and disease severity in HTLV-1-associated myelopathy (HAM/TSP). Blood. 2002; 99(1): 88-94. Epub 2002/01/05. [PubMed: 11756157]

26. Tateno M, Kondo N, Itoh T, Chubachi T, Togashi T, Yoshiki T. Rat lymphoid cell lines with human T cell leukemia virus production. I. Biological and serological characterization. J Exp Med. 1984; 159(4):1105-16. Epub 1984/04/01. [PubMed: 6323614]

27. Perfetto SP, Chattopadhyay PK, Lamoreaux L, Nguyen R, Ambrozak D, Koup RA, et al. Amine reactive dyes: an effective tool to discriminate live and dead cells in polychromatic flow cytometry. J Immunol Methods. 2006b; 313(1-2):199-208. Epub 2006/06/08. [PubMed: 16756987]

28. NIH LANLa. HIV Immunology Database. Los Alamos National Laboratory, Theoretical Biology and Biophysics; Los Alamos, New Mexico: [updated 2009]; Available from: http:// www.hiv.lanl.gov/content/sequence/PEPTGEN/peptgen.html

29. Hersperger AR, Makedonas G, Betts MR. Flow cytometric detection of perforin upregulation in human CD8 T cells. Cytometry Part A. 2008; 73A(11):1050-7.

30. Perfetto SP, Ambrozak D, Nguyen R, Chattopadhyay P, Roederer M. Quality assurance for polychromatic flow cytometry. Nat Protoc. 2006a; 1(3):1522-30. Epub 2007/04/05. [PubMed: 17406444]

31. Roederer M. Spectral compensation for flow cytometry: visualization artifacts, limitations, and caveats. Cytometry. 2001; 45(3):194-205. Epub 2001/12/18. [PubMed: 11746088] 
32. Roederer M, Hardy RR. Frequency difference gating: a multivariate method for identifying subsets that differ between samples. Cytometry. 2001; 45(1):56-64. Epub 2001/10/13. [PubMed: 11598947]

33. Rahman SCJ, Manuel SL, Chehimi J, Montaner LJ, Jain P. Unique Cytokine/Chemokine Signatures for HIV-1 and HCV Mono-infection versus Co-infection as Determined by the Luminex® Analyses. J Clin Cell Immunol. 2011 Jan 7.2(1) pii: 1000104.

34. Roederer M, Nozzi JL, Nason MC. SPICE: exploration and analysis of post-cytometric complex multivariate datasets. Cytometry A. 2011; 79(2):167-74. Epub 2011/01/26. [PubMed: 21265010]

35. Araya N, Takahashi K, Sato T, Nakamura T, Sawa C, Hasegawa D, et al. Fucoidan therapy decreases the proviral load in patients with human T-lymphotropic virus type-1-associated neurological disease. Antivir Ther. 1998; 16(1):89-98. Epub 2011/02/12. [PubMed: 21311112]

36. Furukawa Y, Saito M, Matsumoto W, Usuku K, Tanaka Y, Izumo S, et al. Different cytokine production in tax-expressing cells between patients with human $\mathrm{T}$ cell lymphotropic virus type I (HTLV-I)-associated myelopathy/tropical spastic paraparesis and asymptomatic HTLV-I carriers. J Infect Dis. 2003; 187(7):1116-25. Epub 2003/03/28. [PubMed: 12660926]

37. Fanales-Belasio E, Moretti S, Nappi F, Barillari G, Micheletti F, Cafaro A, et al. Native HIV-1 Tat protein targets monocyte-derived dendritic cells and enhances their maturation, function, and antigen-specific T cell responses. J Immunol. 2002; 168(1):197-206. Epub 2001/12/26. [PubMed: 11751963]

38. Abdelbary NH, Abdullah HM, Matsuzaki T, Hayashi D, Tanaka Y, Takashima H, et al. Reduced Tim-3 expression on human T-lymphotropic virus type I (HTLV-I) Tax-specific cytotoxic T lymphocytes in HTLV-I infection. J Infect Dis. 2011; 203(7):948-59. Epub 2011/03/16. [PubMed: 21402546]

39. Petrovas C, Chaon B, Ambrozak DR, Price DA, Melenhorst JJ, Hill BJ, et al. Differential association of programmed death-1 and CD57 with ex vivo survival of CD8+ T cells in HIV infection. J Immunol. 2009; 183(2):1120-32. Epub 2009/07/01. [PubMed: 19564339]

40. Samimi S, Benoit B, Evans K, Wherry EJ, Showe L, Wysocka M, et al. Increased programmed death-1 expression on CD4+ T cells in cutaneous T-cell lymphoma: implications for immune suppression. Arch Dermatol. 2010; 146(12):1382-8. Epub 2010/08/18. [PubMed: 20713771]

41. Koizumi H, Hashimoto M, Fujiwara M, Murakoshi H, Chikata T, Borghan MA, et al. Different In Vivo Effects of HIV-1 Immunodominant Epitope-Specific Cytotoxic T Lymphocytes on Selection of Escape Mutant Viruses. J Virol. 2010; 84(11):5508-19. [PubMed: 20335254]

42. Rosignoli GLC, Bower M, Gotch F, Imami N. Programmed death (PD)-1 molecule and its ligand PD-L1 distribution among memory CD4 and CD8 T cell subsets in human immunodeficiency virus-1-infected individuals. Clin Exp Immunol. 2009 Jul; 157(1):90-7. 101111/ j1365-2249200903960x. [PubMed: 19659774]

43. Bangham C. HTLV-1 infection: role of CTL efficiency. Blood. 2008; 112:2176-7. [PubMed: 18779398]

44. Jacobson S, Shida H, McFarlin DE, Fauci AS, Koenig S. Circulating CD8+ cytotoxic T lymphocytes specific for HTLV-I pX in patients with HTLV-I associated neurological disease. Nature. 1990; 348(6298):245-8. Epub 1990/11/15. [PubMed: 2146511]

45. Bieganowska K, Hollsberg P, Buckle GJ, Lim DG, Greten TF, Schneck J, et al. Direct analysis of viral-specific CD8+ T cells with soluble HLA-A2/Tax11-19 tetramer complexes in patients with human T cell lymphotropic virus-associated myelopathy. J Immunol. 1999; 162(3):1765-71. Epub 1999/02/11. [PubMed: 9973440]

46. Kannagi M, Shida H, Igarashi H, Kuruma K, Murai H, Aono Y, et al. Target epitope in the Tax protein of human T-cell leukemia virus type I recognized by class I major histocompatibility complex-restricted cytotoxic T cells. J Virol. 1992; 66(5):2928-33. Epub 1992/05/01. [PubMed: 1373197]

47. Parker CE, Daenke S, Nightingale S, Bangham CRM. Activated, HTLV-1-specific cytotoxic Tlymphocytes are found in healthy seropositives as well as in patients with tropical spastic paraparesis. Virology. 1992; 188(2):628-36. [PubMed: 1374983] 
48. Kozako T, Arima N, Toji S, Masamoto I, Akimoto M, Hamada H, et al. Reduced frequency, diversity, and function of human $\mathrm{T}$ cell leukemia virus type 1-specific CD8+ T cell in adult T cell leukemia patients. J Immunol. 2006; 177(8):5718-26. Epub 2006/10/04. [PubMed: 17015761]

49. Yamano Y, Cohen CJ, Takenouchi N, Yao K, Tomaru U, Li HC, et al. Increased expression of human T lymphocyte virus type I (HTLV-I) Tax11-19 peptide-human histocompatibility leukocyte antigen $\mathrm{A} * 201$ complexes on CD4+CD25+ T Cells detected by peptide-specific, major histocompatibility complex-restricted antibodies in patients with HTLV-I-associated neurologic disease. J Exp Med. 2004; 199(10):1367-77. [PubMed: 15136590]

50. Bieganowska K, Hollsberg P, Buckle G, Lim D, Greten T, Schneck J, et al. Direct analysis of viralspecific CD8+ T cells with soluble HLA-A2/Tax11-19 tetramer complexes in patients with human T cell lymphotropic virus-associated myelopathy. J Immunol. 1999; 162:1765-71. [PubMed: 9973440]

51. Parker CE, Daenke S, Nightingale S, Bangham CR. Activated, HTLV-1-specific cytotoxic Tlymphocytes are found in healthy seropositives as well as in patients with tropical spastic paraparesis. Virology. 1992; 188(2):628-36. Epub 1992/06/01. [PubMed: 1374983]

52. Gruener N, Lechner F, Jung M, Diepolder H, Gerlach T, Lauer G, et al. Sustained dysfunction of antiviral CD8+ T lymphocytes after infection with hepatitis C virus. J Virol. 2001; 75:5550-8. [PubMed: 11356962]

53. Klenerman P, Hill A. T cells and viral persistence: lessons from diverse infections. Nat Immunol. 2005; 6:873-9. [PubMed: 16116467]

54. Kostense S, Vandenberghe K, Joling J, Van Baarle D, Nanlohy N, Manting E, et al. Persistent numbers of tetramer+ CD8(+) T cells, but loss of interferon-gamma+ HIV-specific T cells during progression to AIDS. Blood. 2002; 99:2505-11. [PubMed: 11895786]

55. Shankar P, Russo M, Harnisch B, Patterson M, Skolnik P, Lieberman J. Impaired function of circulating HIV-specific CD8(+) T cells in chronic human immunodeficiency virus infection. Blood. 2000; 96:3094-101. [PubMed: 11049989]

56. Wherry E, Blattman J, Murali-Krishna K, van der Most R, Ahmed R. Viral persistence alters CD8 T-cell immunodominance and tissue distribution and results in distinct stages of functional impairment. J Virol. 2003; 77:4911-27. [PubMed: 12663797]

57. Kannagi M, Hasegawa A, Takamori A, Kinpara S, Utsunomiya A. The roles of acquired and innate immunity in human T-cell leukemia virus type 1-mediated diseases. Frontiers in microbiology. 2012; 3:323. Epub 2012/09/13. [PubMed: 22969761]

58. Johnson-Nauroth JM, Graber J, Yao K, Jacobson S, Calabresi PA. Memory lineage relationships in HTLV-1-specific CD8+ cytotoxic T cells. J Neuroimmunol. 2006; 176(1-2):115-24. Epub 2006/06/03. [PubMed: 16740321]

59. Vine AM, Heaps AG, Kaftantzi L, Mosley A, Asquith B, Witkover A, et al. The Role of CTLs in Persistent Viral Infection: Cytolytic Gene Expression in CD8+ Lymphocytes Distinguishes between Individuals with a High or Low Proviral Load of Human T Cell Lymphotropic Virus Type 1. The Journal of Immunology. 2004; 173(8):5121-9. [PubMed: 15470056]

60. Grant C, Oh U, Yao K, Yamano Y, Jacobson S. Dysregulation of TGF- $\beta$ signaling and regulatory and effector T-cell function in virus-induced neuroinflammatory disease. Blood. 2008; 111(12): 5601-9. [PubMed: 18326816]

61. Biddison WE, Kubota R, Kawanishi T, Taub DD, Cruikshank WW, Center DM, et al. Human T cell leukemia virus type I (HTLV-I)-specific CD8+ CTL clones from patients with HTLV-Iassociated neurologic disease secrete proinflammatory cytokines, chemokines, and matrix metalloproteinase. J Immunol. 1997; 159(4):2018-25. Epub 1997/08/15. [PubMed: 9257869]

62. Barber DL, Wherry EJ, Masopust D, Zhu B, Allison JP, Sharpe AH, et al. Restoring function in exhausted CD8 T cells during chronic viral infection. Nature. 2006; 439(7077):682-7. Epub 2005/12/31. [PubMed: 16382236]

63. Freeman G, Long A, Iwai Y, Bourque K, Chernova T, Nishimura H, et al. Engagement of the PD-1 immunoinhibitory receptor by a novel B7 family member leads to negative regulation of lymphocyte activation. J Exp Med. 2000; 192:1027-34. [PubMed: 11015443] 
64. Kozako T, Yoshimitsu M, Fujiwara H, Masamoto I, Horai S, White Y, et al. PD-1/PD-L1 expression in human T-cell leukemia virus type 1 carriers and adult T-cell leukemia/lymphoma patients. Leukemia. 2009; 23(2):375-82. Epub 2008/10/03. [PubMed: 18830259]

65. Kozako T, Yoshimitsu M, Akimoto M, White Y, Matsushita K, Soeda S, et al. Programmed death-1 (PD-1)/PD-1 ligand pathway-mediated immune responses against human T-lymphotropic virus type 1 (HTLV-1) in HTLV-1-associated myelopathy/tropical spastic paraparesis and carriers with autoimmune disorders. Human immunology. 2011; 72(11):1001-6. [PubMed: 21851845]

66. Abdelbary NH, Abdullah HM, Matsuzaki T, Hayashi D, Tanaka Y, Takashima H, et al. Reduced Tim-3 Expression on Human T-lymphotropic Virus Type I (HTLV-I) Tax-specific Cytotoxic T Lymphocytes in HTLV-I Infection. Journal of Infectious Diseases. 2011; 203(7):948-59. [PubMed: 21402546]

67. Ndhlovu LC, Leal FE, Hasenkrug AM, Jha AR, Carvalho KI, Eccles-James IG, et al. HTLV-1 Tax Specific CD8+ T Cells Express Low Levels of Tim-3 in HTLV-1 Infection: Implications for Progression to Neurological Complications. PLoS Negl Trop Dis. 2011; 5(4):e1030. [PubMed: 21541358]

68. Asquith B, Bangham CR. The role of cytotoxic T lymphocytes in human T-cell lymphotropic virus type 1 infection. Journal of theoretical biology. 2000; 207(1):65-79. Epub 2000/10/12. [PubMed: 11027480]

69. Nowak MA, Bangham CR. Population dynamics of immune responses to persistent viruses. Science. 1996; 272(5258):74-9. Epub 1996/04/05. [PubMed: 8600540] 


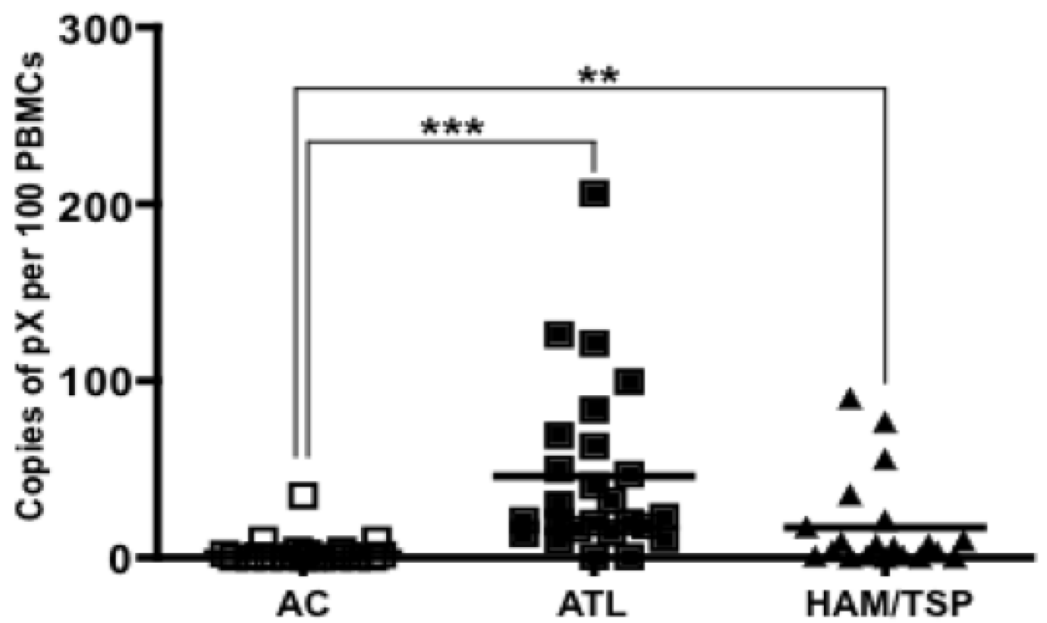

Figure 1.

Comparison of proviral loads in ACs, ATL patients, and HAM/TSP patients. Total DNA was isolated from PBMCs and proviral load was determined by the quantitative TaqMan real-time PCR as described in Materials and Methods. At least two replicates per donor were processed and proviral loads were compared between AC, ATL and HAM/TSP by a twotailed, unpaired nonparametric t test (Mann-Whitney) to determine $\mathrm{P}$ values. **denotes $\mathrm{P} \leq$ 0.01 and $* * *$ denotes $\mathrm{P} \leq 0.001$. The horizontal line in the graphs represents the median values. 
A
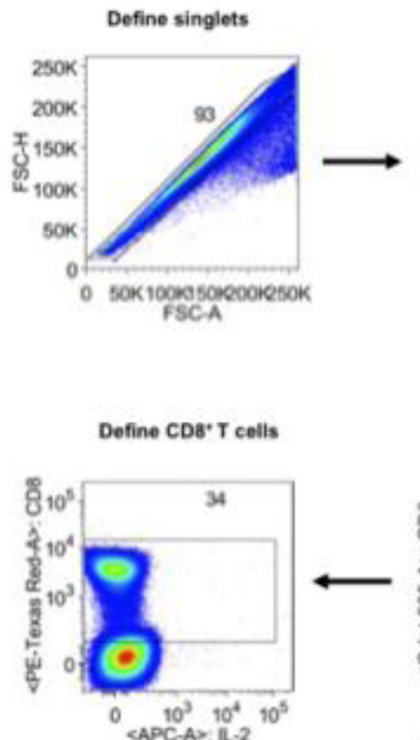

B

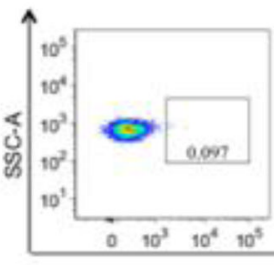

Remove junk

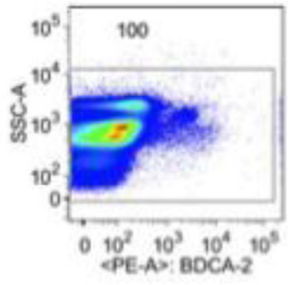

Define $\mathrm{CD}^{3}+\mathrm{T}$ cells

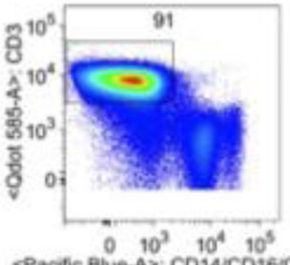

opacific Blue-A> CD14/CO16rCD19

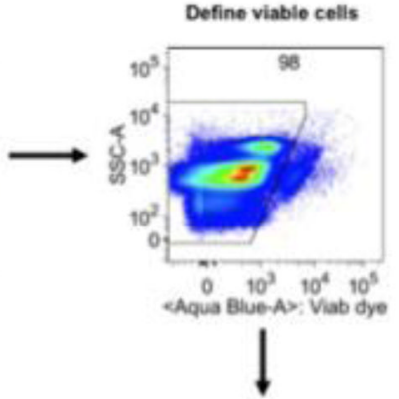

Define lymphocytes

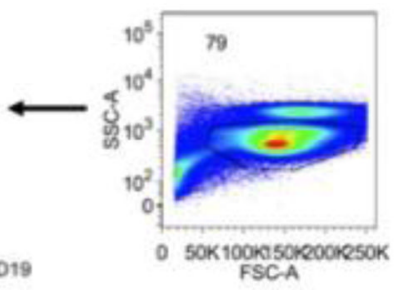

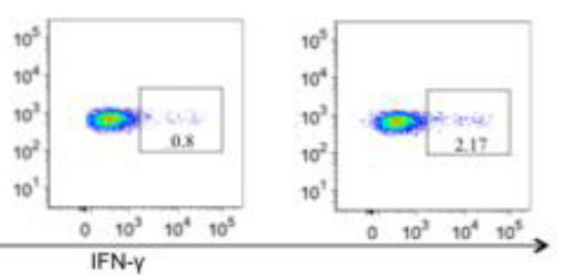

C

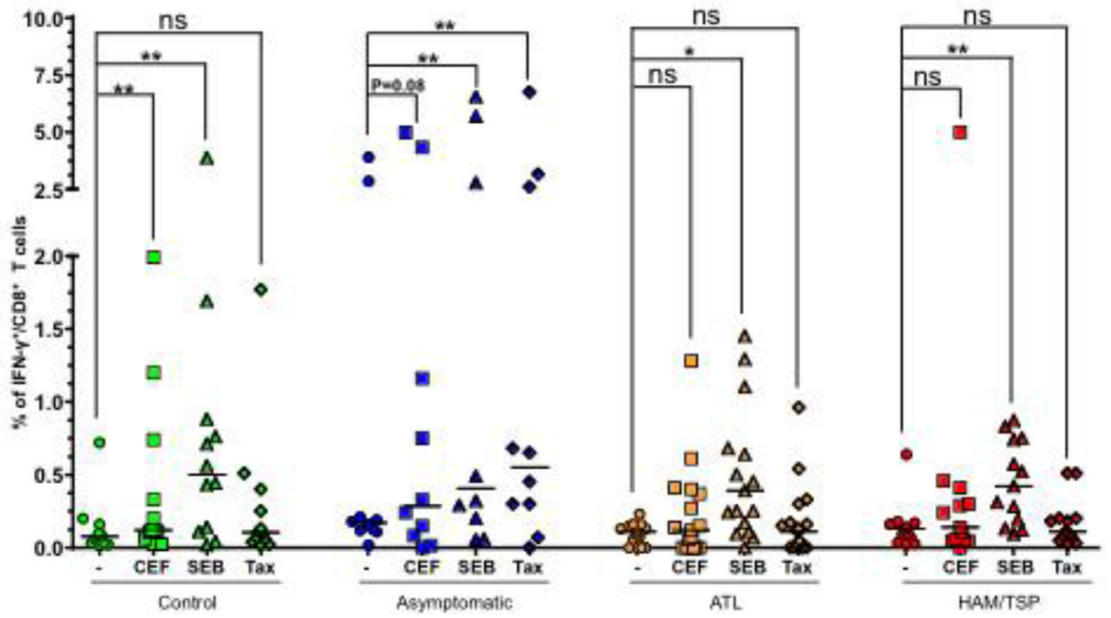

Figure 2.

(A) Gating strategy for T cells. Aggregate of two or more cells were first excluded by plotting forward scatter height (FSC-H) versus forward scatter area (FSC-A). A series of dump gates were created to exclude all the cells except $\mathrm{CD} 8^{+} \mathrm{T}$ cells. (B) A representative plot of total interferon gamma production from the $\mathrm{CD} 8^{+} \mathrm{T}$ cells from a control donor upon non-stimulation or stimulation with CEF and SEB. (C) Percentage of CD8 ${ }^{+} / \mathrm{IFN}-\gamma^{+} \mathrm{T}$ cells were detected by flow cytometry and compared within the group by a two-tailed, paired non-parametric $t$ test (Wilcoxon) to determine $\mathrm{P}$ values. The horizontal line in the graphs represents the median values. *denotes $\mathrm{P} \leq 0.05$. 
A

Figure 3.

Differentiation and activation state of $\mathrm{CD} 8^{+} \mathrm{T}$ cells among clinical groups. PBMCs from controls, ACs, ATL and HAM/TSP patients were stimulated with CEF, SEB and Tax. After stimulation, $\mathrm{CD} 27$ and $\mathrm{CD} 45 \mathrm{RO}$ were used as markers to differentiate between naïve, effector and memory phenotypes of $\mathrm{CD} 8^{+} \mathrm{T}$ cells. (A) naïve $\left(\mathrm{CD} 27^{+} / \mathrm{CD} 45 \mathrm{RO}^{-}\right)$, (B) effector $\left(\mathrm{CD} 27^{-} / \mathrm{CD}^{2} 5 \mathrm{RO}^{-}\right)$, (C) central memory $\left(\mathrm{CD} 27^{+} / \mathrm{CD}^{2} 5 \mathrm{RO}^{+}\right)$and, (D) Effector memory $\left(\mathrm{CD} 27^{-} / \mathrm{CD}^{2} 5 \mathrm{RO}^{+}\right)$subsets were defined. The horizontal line in the graphs represents the median values. $\mathrm{P}$ values for statistical comparisons within a group were calculated using two-tailed, non-parametric paired t test (Wilcoxon). $\mathrm{P}$ values between two groups were calculated using two-tailed non-parametric unpaired t test (Mann Whitney). 
$* *$ denotes $\mathrm{P} \leq 0.01$. Please note that our findings with CEF and SEB are similar and therefore the comparisons for CEF have not been shown for simplifying the figure and make it easy to understand. 
A

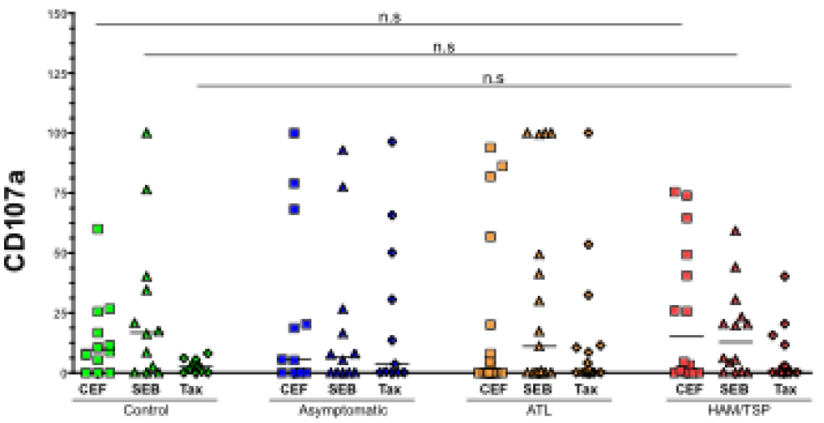

B

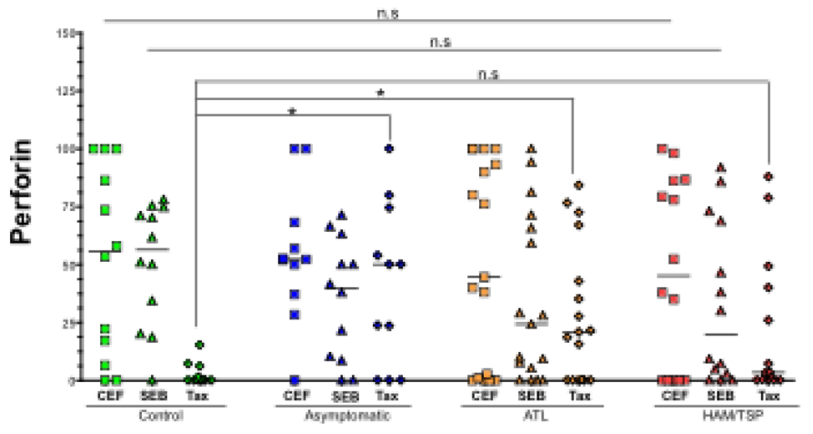

C

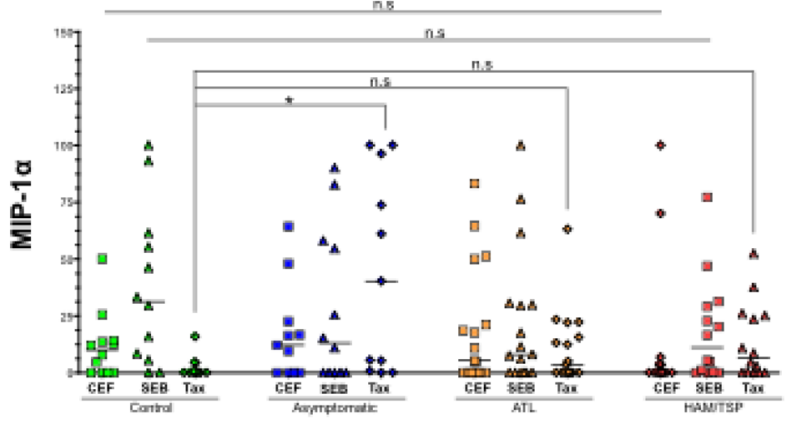

D

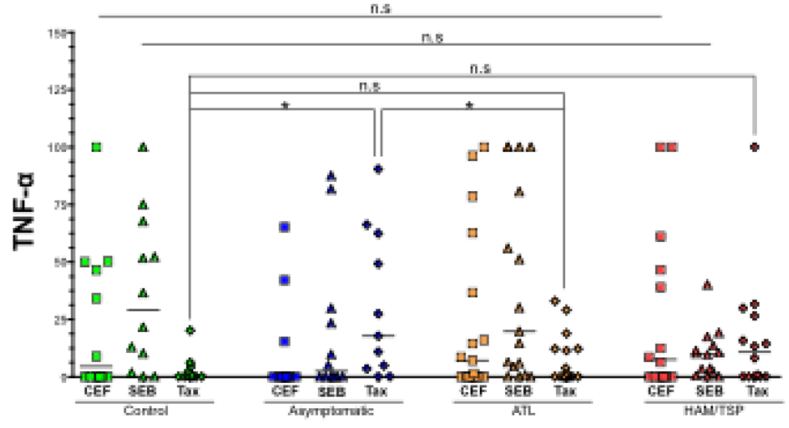

Figure 4.

Expression of various T-cell functional markers on IFN- $\gamma^{+} / \mathrm{CD}^{+} \mathrm{T}$ cells: $\mathrm{SEB}$ and Tax stimulated PBMCs from each clinical group were gated for $\mathrm{CD} 8^{+} / \mathrm{IFN}-\gamma^{+} \mathrm{T}$ cells using flow cytometry (gating strategy similar to the one depicted in Fig. 2). Expression of four CTL markers was measured. (A) CD107a, (B) perforin, (C) MIP-1a, and (D) Expression of each marker in response to SEB and Tax was compared across all groups. The horizontal line in the graphs represents the median values. $\mathrm{P}$ values for statistical comparisons between two groups were calculated using two-tailed non-parametric unpaired t test (Mann Whitney). $*$ denotes $\mathrm{P} \leq 0.05$. 

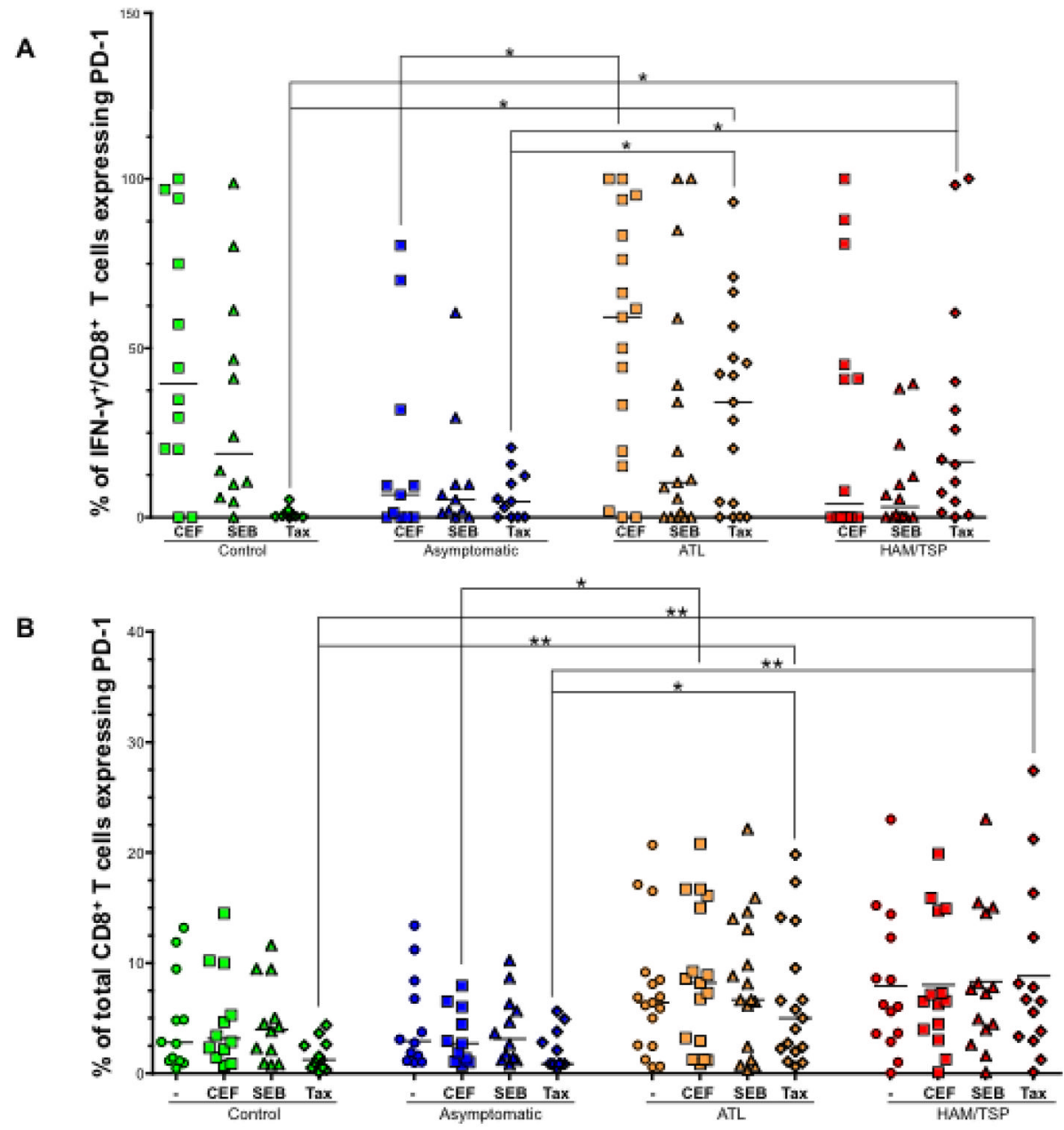

C

\section{Control}

$A C$

ATL

HAM/TSP

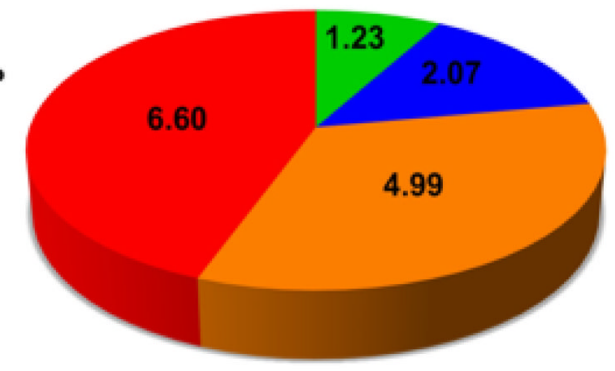

Figure 5.

CTLs in ATL and HAM/TSP patients upregulate PD-1 expression. PBMCs from each clinical group were stimulated with CEF, SEB and Tax. After stimulation, PD-1 expression was measured on (A) $\mathrm{CD} 8^{+} / \mathrm{IFN}-\gamma^{+} \mathrm{T}$ cells and B) total $\mathrm{CD} 8^{+} \mathrm{T}$ cells. The horizontal line represents the median value. $\mathrm{P}$ values for statistical comparisons between two groups were made using two-tailed non-parametric unpaired t test (Mann Whitney). *denotes $\mathrm{P} \leq 0.05$ and $* *$ denotes $\mathrm{P} \leq 0.01$. 
Arc:

PD-1

CEF

SEB

Tax
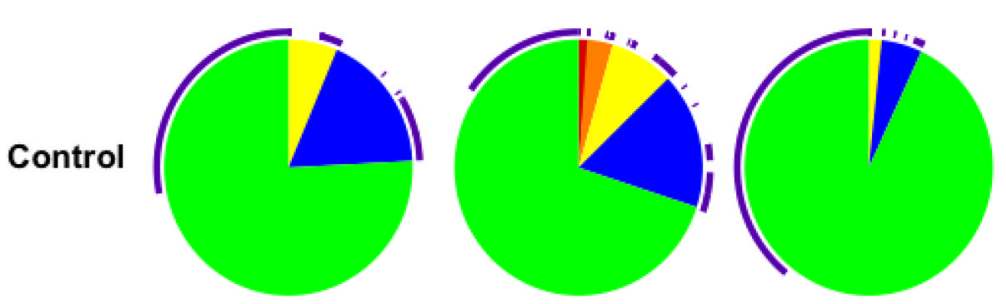

AC
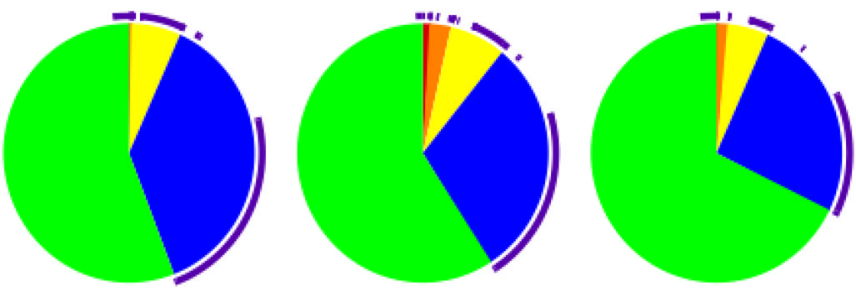

ATL
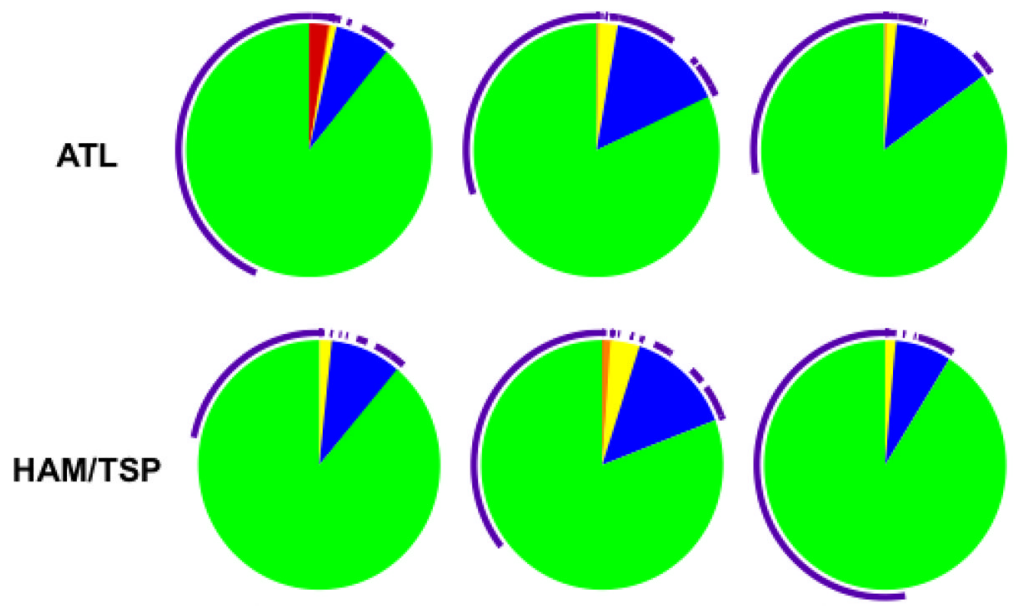

No. of functions:

\section{5}

4

3

1

Figure 6.

Distinct polyfunctional profiles distinguish ACs from diseased groups. PBMCs were stimulated with CEF, SEB and Tax and the average polyfunctionality profile of $\mathrm{CD}^{+} \mathrm{T}$ cells was symbolized as a pie chart and stratified by stimulation type (CEF, SEB, or Tax) and patient category. Pie slices represent the proportion of $\mathrm{CD} 8^{+} \mathrm{T}$ cells that upregulated 5, $4,3,2$, or 1 function. Purple arc denotes the proportion of PD-1 expressing cells within each slice. 


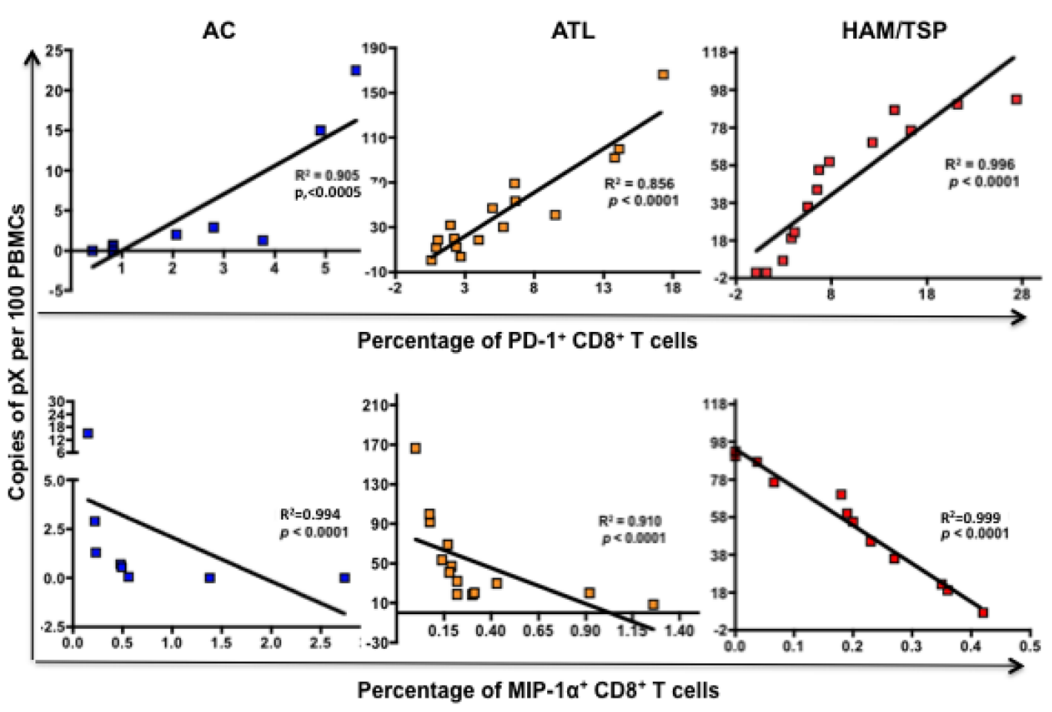

Figure 7.

Correlation between PD-1 and MIP-1a expression on total CD8 ${ }^{+} \mathrm{T}$ cells with proviral load in ACs, ATL and HAM/TSP patients. Upper panel: proviral loads of ACs, ATL, and HAM/ TSP patients (as plotted in Fig. 1) were correlated to the amount of PD-1 expressed on total $\mathrm{CD}^{+} \mathrm{T}$ cells (after stimulation of PBMCs with CEF, SEB, and Tax) in each sample and plotted on X-Y scatter. A Spearman correlation was calculated using Prism 4.0 C software. Both $\mathrm{R}^{2}$ and $P$ values are reported. Lower panel; Similar to PD-1, MIP-1a expression was correlated to the proviral load. 


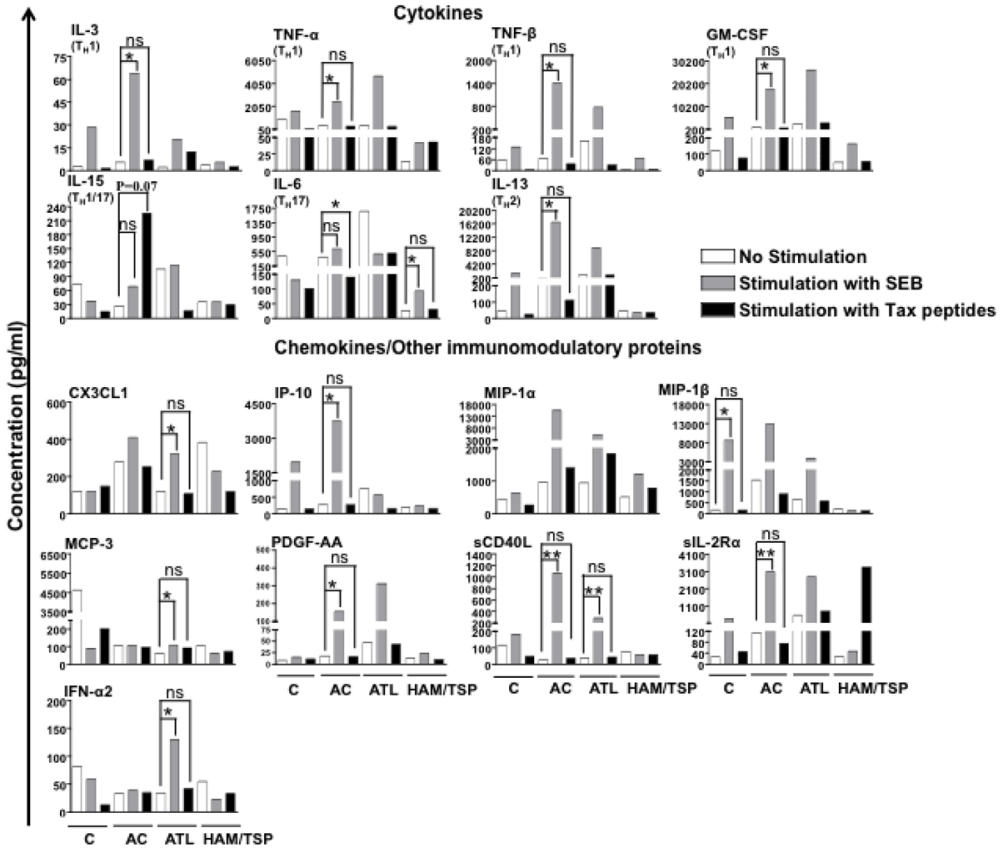

Figure 8.

Cytokine/Chemokine secretion profile of PBMCs in response to SEB and Tax stimulation. 42-plex luminex assay was used for simultaneous quantification of 42 analytes (including cytokines, chemokines, and other immunomodulatory proteins) in the cell culture supernatant. The concentrations of few analytes in the supernatant were below the limit of detection and were thus excluded from analyses. The horizontal line in the graphs represents median values. $\mathrm{P}$ values for statistical comparisons within a group were calculated using two-tailed, non-parametric paired t test (Wilcoxon). *denotes $\mathrm{P} \leq 0.05$ and $* *$ denotes $\mathrm{P} \leq$ 0.01 . The $\mathrm{P}$ value for comparison of IL-15 levels between unstimulated and Tax stimulated group was 0.07 . 
Table 1

Summary of Jamaican cohort

\begin{tabular}{|c|c|c|}
\hline \multicolumn{3}{|c|}{ Seronegative Control } \\
\hline $\mathrm{S} / \mathrm{N}^{*}$ & Race & Age \\
\hline F1 & Asian/Pacific & 45 \\
\hline F2 & Black & 23 \\
\hline F3 & Black & 66 \\
\hline $\mathrm{F} 4$ & Black & 17 \\
\hline F5 & Black & 51 \\
\hline F6 & Black & 40 \\
\hline F7 & Black & 50 \\
\hline F8 & Black & 42 \\
\hline F9 & Black & 65 \\
\hline F10 & Black & 52 \\
\hline F11 & Black & 46 \\
\hline M1 & Other & 29 \\
\hline M2 & Black & 69 \\
\hline M3 & Black & 62 \\
\hline M4 & Black & 24 \\
\hline M5 & Black & 28 \\
\hline M6 & Black & 47 \\
\hline \multicolumn{3}{|c|}{ Asymptomatic carriers } \\
\hline $\mathrm{S} / \mathrm{N}$ & Race & Age \\
\hline $\mathrm{F} 1$ & Black & 57 \\
\hline $\mathrm{F} 2$ & Black & 19 \\
\hline F3 & Black & 23 \\
\hline $\mathrm{F} 4$ & Black & 40 \\
\hline F5 & Black & 62 \\
\hline F6 & Black & 43 \\
\hline F7 & Black & 40 \\
\hline F8 & Black & 42 \\
\hline F9 & Black & 40 \\
\hline F10 & Black & 46 \\
\hline F11 & Black & 49 \\
\hline M1 & Black & 73 \\
\hline M2 & Black & 45 \\
\hline M3 & Black & 30 \\
\hline M4 & Black & 19 \\
\hline M5 & Black & 13 \\
\hline M6 & Black & 63 \\
\hline
\end{tabular}




\begin{tabular}{|c|c|c|}
\hline \multicolumn{3}{|c|}{ Seronegative Control } \\
\hline $\mathbf{S} / \mathbf{N}^{*}$ & Race & Age \\
\hline \multicolumn{3}{|c|}{ ATL patients } \\
\hline $\mathrm{S} / \mathrm{N}$ & Race & Age \\
\hline $\mathrm{F} 1$ & Black & 48 \\
\hline $\mathrm{F} 2$ & Black & 49 \\
\hline $\mathrm{F} 3$ & Black & 53 \\
\hline $\mathrm{F} 4$ & Black & 68 \\
\hline F5 & Black & 49 \\
\hline F6 & Black & 68 \\
\hline F7 & Black & 41 \\
\hline F8 & Black & 27 \\
\hline F9 & Black & 20 \\
\hline F10 & Black & 51 \\
\hline F11 & Black & 41 \\
\hline M1 & Black & 30 \\
\hline M2 & Black & 57 \\
\hline M3 & Black & 22 \\
\hline M4 & Other & 25 \\
\hline M5 & Other & 46 \\
\hline M6 & Other & 75 \\
\hline \multicolumn{3}{|c|}{ HAM/TSP patients } \\
\hline $\mathrm{S} / \mathrm{N}$ & Race & Age \\
\hline $\mathrm{F} 1$ & Black & 41 \\
\hline $\mathrm{F} 2$ & Black & 23 \\
\hline F3 & Black & 49 \\
\hline $\mathrm{F} 4$ & Black & 42 \\
\hline F5 & Black/White & 51 \\
\hline F6 & Black & 19 \\
\hline F7 & Black & 47 \\
\hline F8 & Black & 64 \\
\hline F9 & Black & 49 \\
\hline F10 & Black & 63 \\
\hline M1 & Black & 16 \\
\hline M2 & Black & 22 \\
\hline M3 & Black & 75 \\
\hline M4 & Black & 46 \\
\hline M5 & Black & 57 \\
\hline M6 & Black & 31 \\
\hline M7 & Black & 57 \\
\hline
\end{tabular}


F stands for female, $M$ for male 